\title{
Multi-procedure management in an eyeglasses-related open globe injury
}

\author{
Piotr Skopiński ${ }^{1,2}$, Małgorzata Woronkowicz ${ }^{1}$, Ewa Langwińska-Wośko ${ }^{1}$, Magdalena Korwin $^{1}$, Wojciech Kołodziejczyk ${ }^{1}$, \\ Anna Maria Ambroziak ${ }^{1,3}$ \\ ${ }^{1}$ Department of Ophthalmology, Medical University of Warsaw, Poland \\ ${ }^{2}$ Department of Histology and Embryology, Biostructure Center, Medical University of Warsaw, Poland \\ ${ }^{3}$ Faculty of Physics, University of Warsaw, Poland
}

Videosurgery Miniinv 2014; 9 (1): 101-106

DOI: $10.5114 /$ wiitm.2013.40104

\begin{abstract}
We present a case of successful multi-procedure management of a patient with an open globe injury. A 47-year-old man sustained an injury to his left eye caused by glass fragments of his own spectacles shattered while he was protecting an unknown woman from physical assault at a bus stop. Over a span of 65 months the patient underwent multiple procedures including primary wound repair, penetrating keratoplasty combined with extracapsular cataract extraction, neodymium : YAG laser capsulotomy, and laser-assisted subepithelial keratectomy (LASEK), and had a successfully treated episode of corneal graft rejection. This sequence of treatment substantially improved his left eye vision from hand movements at the time of admission to 0.9-0.5 $\times 90$ at the last follow-up nearly 10 years after the trauma. Proper initial surgical management of an open globe injury can create the possibility for virtually complete vision restoration.
\end{abstract}

Key words: open globe injury, eyeglasses-related injury, ocular trauma score, classification and regression tree.

\section{Introduction}

Among eye damage caused by a variety of different objects, those related to eyeglass wear seem to be especially unfortunate. In all such instances, spectacles which are meant primarily to serve as a vision aid become a double-edged sword. Eyeglasses as a risk factor for an ocular injury attracted more attention in the literature following the widespread introduction of airbags in cars [1, 2]. Frames and screws, as elements of spectacles, have also been reported to constitute a threat of eye trauma $[2,3]$. This report demonstrates the multi-procedure management and the long-term outcome of a serious eye trauma caused by eyeglasses in an assault-related injury.

\section{Case report}

A 47-year-old man presented to our emergency department with pain and decreased vision in his left eye in March 2003. Two hours earlier the patient sustained an injury to his left eye caused by glass fragments of his own spectacles (OD: $-0.75-1.25 \times 90$; OS:- $1.0-0.75 \times 90$ ) which shattered while he was protecting an unknown woman from a physical assault at a bus stop. On examination his visual acuity (VA) in the injured eye was hand motions in front of the eye with proper light perception in all quadrants. Slit-lamp biomicroscopy revealed upper and lower lid lacerations, mild corneal edema, a full-thickness nasal sclerocorneal laceration $10 \mathrm{~mm}$ long with uvea and vitreous prolapse and a $5 \mathrm{~mm}$ central linear

\section{Address for correspondence}

Małgorzata Woronkowicz MD, Department of Ophthalmology, Medical University of Warsaw, 13 Sierakowskiego St, 03-709 Warsaw,

Poland, e-mail: malwor@poczta.onet.pl 
horizontal corneal laceration (zone II of the wound location according to the Ocular Trauma Classification Group [4]). The anterior chamber was shallow with $1 \mathrm{~mm}$ hyphema and the eye was hypotonic with a positive Seidel test. The pupil was irregular with presence of direct and consensual light reflexes. The crystalline lens was in place and seemed intact but was not totally visible. The posterior segment visualization was limited to a red reflex. The right eye was unremarkable except for low myopia and astigmatism. X-ray of the skull and orbit showed no bony fractures. The same day exploration of the globe demonstrated no additional perforations and the patient underwent a primary wound repair. Firstly, the prolapsed iris was repositioned and the vitreous was removed from the wound. Furthermore, the anterior chamber was irrigated and reconstructed and the perforations were closed with 10-0 monofilament nylon to the cornea and 6-0 vicryl to the sclera. Finally, the eyelid lacerations were sutured with 7-0 nylon. On the first postoperative day, VA improved to 0.02 with a pinhole in Snellen decimal units (Figure 1) and intraocular pressure reached normal limits on palpation, remaining stable without medication. Ultrasound biomicroscopy (UBM) excluded anterior segment intraocular foreign bodies and no posteri- or segment abnormalities were noted on the B-scan ultrasonography (USG). The postoperative regimen included a systemic steroid along with a topical one, nonsteroidal anti-inflammatory agent, antibiotic, cycloplegic and dexpanthenol. After discharge from the hospital the patient was examined periodically and his vision continued to improve. Further sutures removal and fitting with rigid gas permeable contact lenses allowed best corrected visual acuity (BCVA) of 0.5 on follow-up 7 months later. However, cataract formation was noted as having developed probably as a result of both the injury and treatment with systemic and topical steroids. In addition, the patient started to experience significant decrease in contact lenses tolerance as a result of dry eye syndrome. Therefore, 3 years after the trauma penetrating keratoplasty combined with extracapsular cataract extraction with intraocular lens (IOL) implantation was performed. Due to the linear central corneal scar in the left eye (Photo 1) IOL power calculation was based on keratometry from the fellow healthy eye. Hence, postoperatively the best spectacle-corrected VA was 0.7 with -7.25-3.5 × 145 (Photo 2) and hybrid contact lenses were prescribed as an alternative. Four and a half years following the injury, the patient presented with VA deterioration to 0.5 caused by

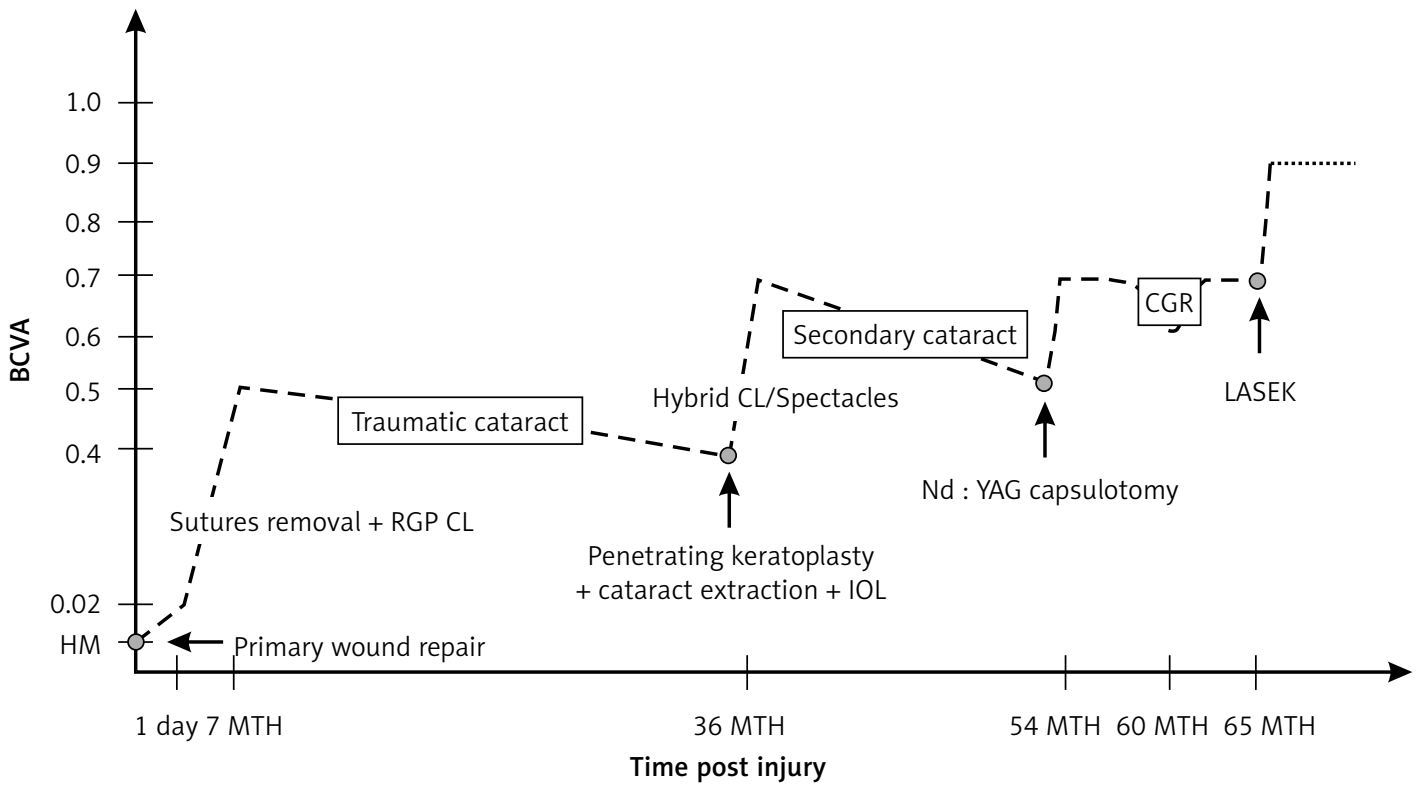

MTH - month, CL - contact lenses, $1 O L$ - intraocular lens, CGR - corneal graft rejection

Figure 1. Changes in best corrected visual acuity (BCVA) in Snellen decimal units throughout the whole follow-up period 


\section{-orbscan}

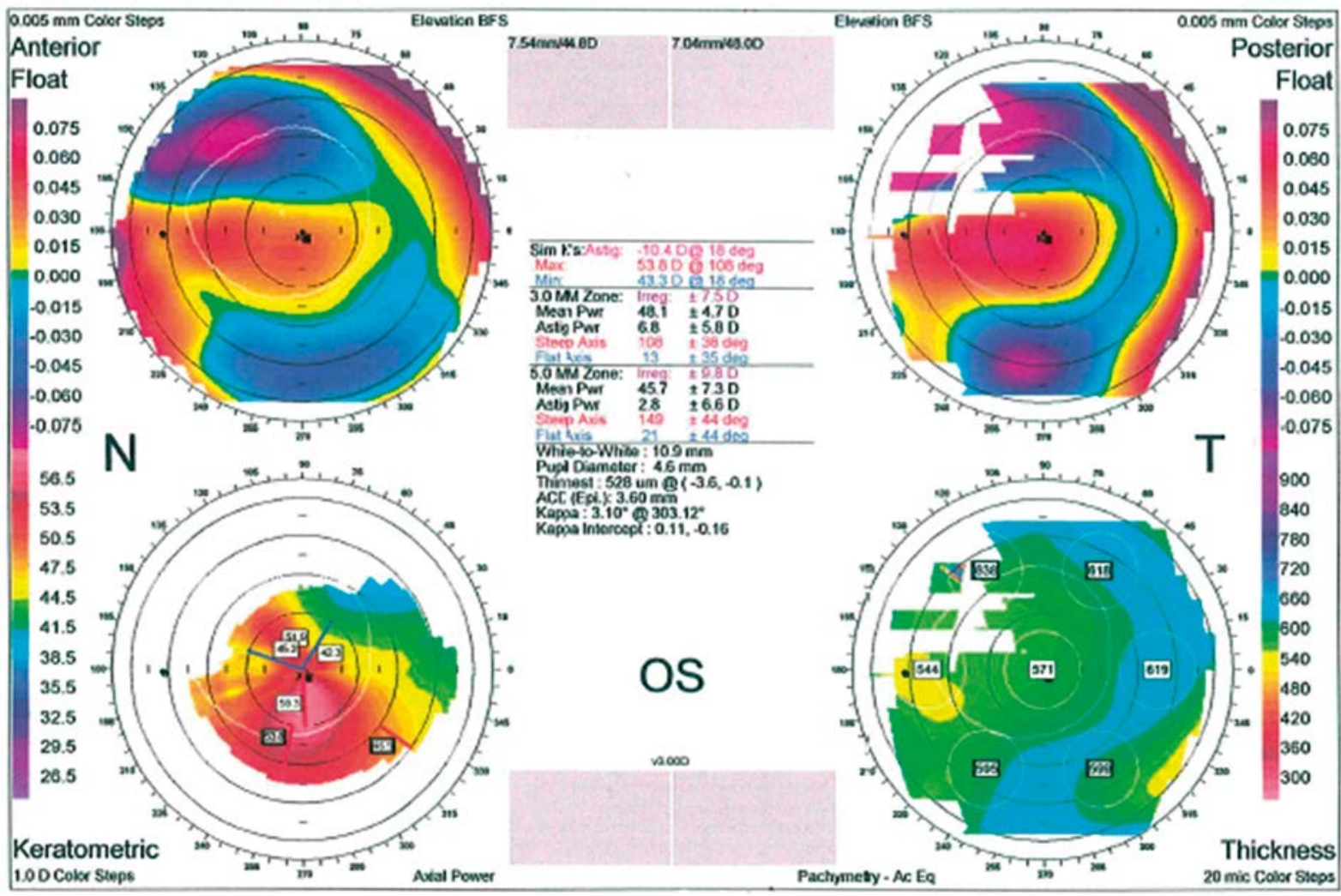

Photo 1. Slit-scanning corneal topography (Orbscan by Orbtek Bausch \& Lomb) showing corneal astigma-

tism 7 months after sutures removal

posterior capsular opacification. Routine Nd:YAG laser capsulotomy was conducted resulting in regaining VA previous to cataract development. Six months later, the patient had a successfully treated episode of corneal graft rejection. Finally, five and a half years after the initial injury laser-assisted subepithelial keratectomy (LASEK) was performed which led to nearly perfect VA of 0.9 with $-0.5 \times 90$ (Photo 3). Postoperative recovery was uneventful and the BCVA was maintained at the most recent follow-up nearly 10 years after the trauma.

\section{Discussion}

An open eye injury defined as a full-thickness wound of the eye wall according to the Birmingham Eye Trauma Terminology (BETT) system [5] is a potentially sight-threatening condition. An individual vision outcome after an eye injury may be relatively favorable even in cases which appear to be hopeless at the time of presentation. Therefore, each time surgeons should persevere in their efforts to reconstruct the globe regardless of the scale of the injury. However, setting realistic expectations in terms of visual acuity is crucial since consequences of trauma deeply affect patients' quality of life. It also helps doctors in solving clinical dilemmas regarding management and is of significant importance for the public health organization.

In an attempt to make an individual prognosis of vision after the trauma more accurate, a wide range of variables have been studied. In the literature, the list of single factors which correlate with visual outcome includes: mechanism [6-8], location [7, 9-12], extent of injury [7, 11-15], initial visual acuity [6, 11$16]$, afferent pupillary defect $[6,12,13,15,16]$, adnexal injury [17], hyphema [11, 14, 18], lens involvement [10, 18], massive suprachoroid hemorrhage [19], vitreous hemorrhage $[9,11,12,14]$, retinal detachment [6, 8, 9, 11-13], intraocular foreign body [9], age $[10,20]$, sex [21], and time between injury and the primary repair [18]. However, the contradictory nature of those findings which show statistically 


\section{oorbscan}

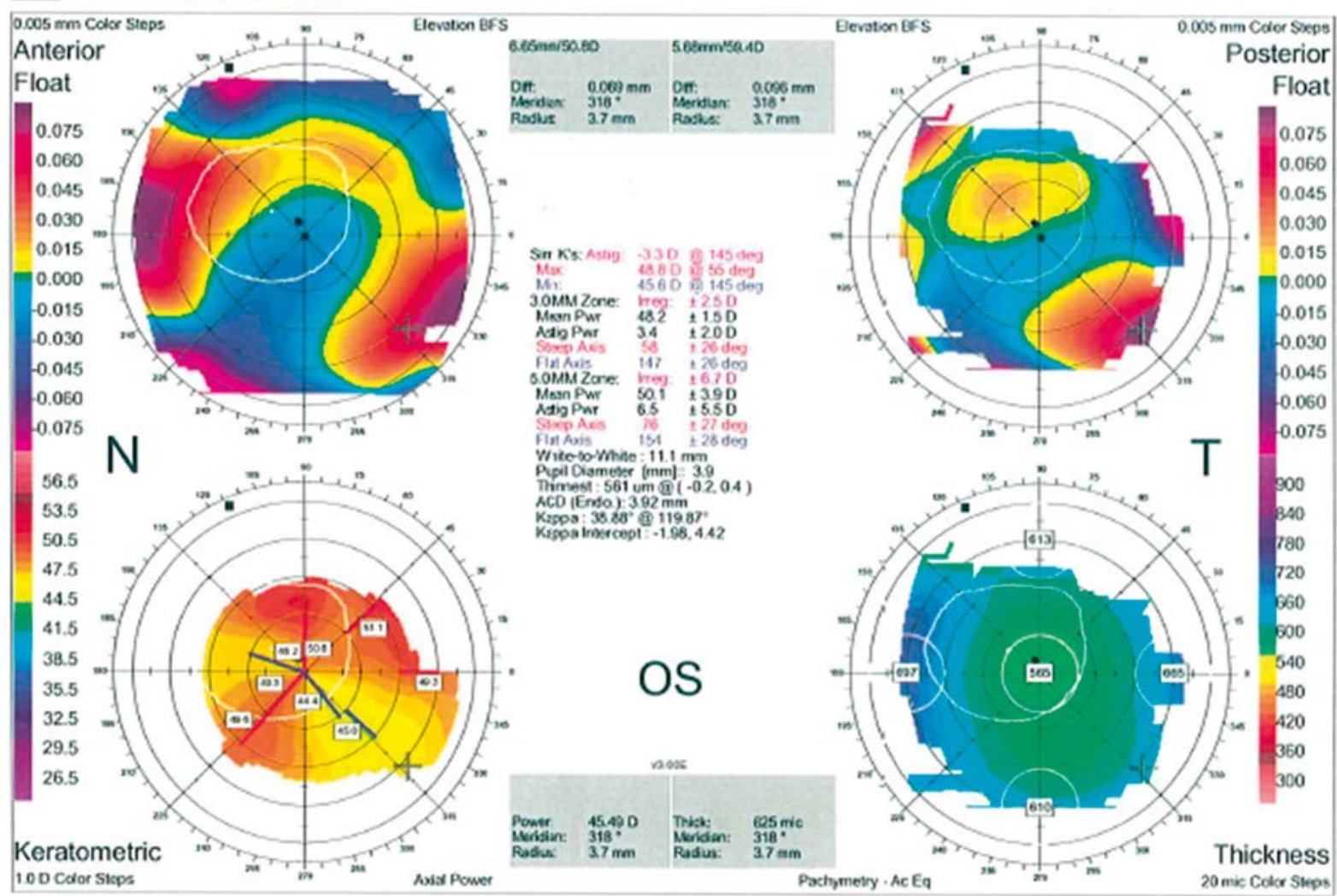

Photo 2. Slit-scanning corneal topography (Orbscan by Orbtek Bausch \& Lomb) showing corneal astigma-

tism 1 year and 4 months after combined penetrating keratoplasty and cataract extraction

significant associations of abovementioned variables and post-traumatic VA in some reports and a lack of them in others makes their practical value limited.

To further address the problem of constructing a reasonable prediction tool for VA after injury, Kuhn et al. created the ocular trauma score (OTS) [22]. This prognostic model is based on an analysis of over 2500 traumatized eyes from the United States and Hungarian Eye Injury Registries. Out of more than 100 variables describing injured eyes, six were identified to carry predictive values, i.e. initial visual acuity, the presence of globe rupture, endophthalmitis, perforating injury, retinal detachment and relative afferent pupillary defect. The OTS score is obtained by ascribing certain numerical raw points to visual acuity divided into 5 categories (the better the vision, the more points). Next, a certain fixed number of points is subtracted for each of the remaining variables present. The total sum belongs to one of five categories and indicates the probability of achieving a range of visual acuity shortly after the trauma. In our case the overall calculated category of the ocular trauma score (OTS) was 3, which comes from assigning 70 points for VA of hand motions. Hence, the likelihood of no light perception was $2 \%$, light perception to hand motion - 11\%, 1/200-19/200 - 15\%, $20 / 200-20 / 50-15 \%$, and $20 / 40$ or better $-15 \%$.

In 2008 Schmidt et al. described another prognostic model called the classification and regression tree (CART) [23]. In order to predict visual outcome following open globe injury they analyzed 214 records of ocular trauma at the Wilmer Ophthalmological Institute. The statistical method they used is known as binary recursive partitioning, which generates a tree diagram. The first node in this model is represented by relative afferent pupillary defect. As the highest discriminatory variable it best separates the data into the new outcome categories. Other steps include initial VA, lid laceration and wound location, which all are split dichotomously. The end points of each branch are ocular survival versus no vision outcome represented in percentages of the 


\section{TORBSCAN}

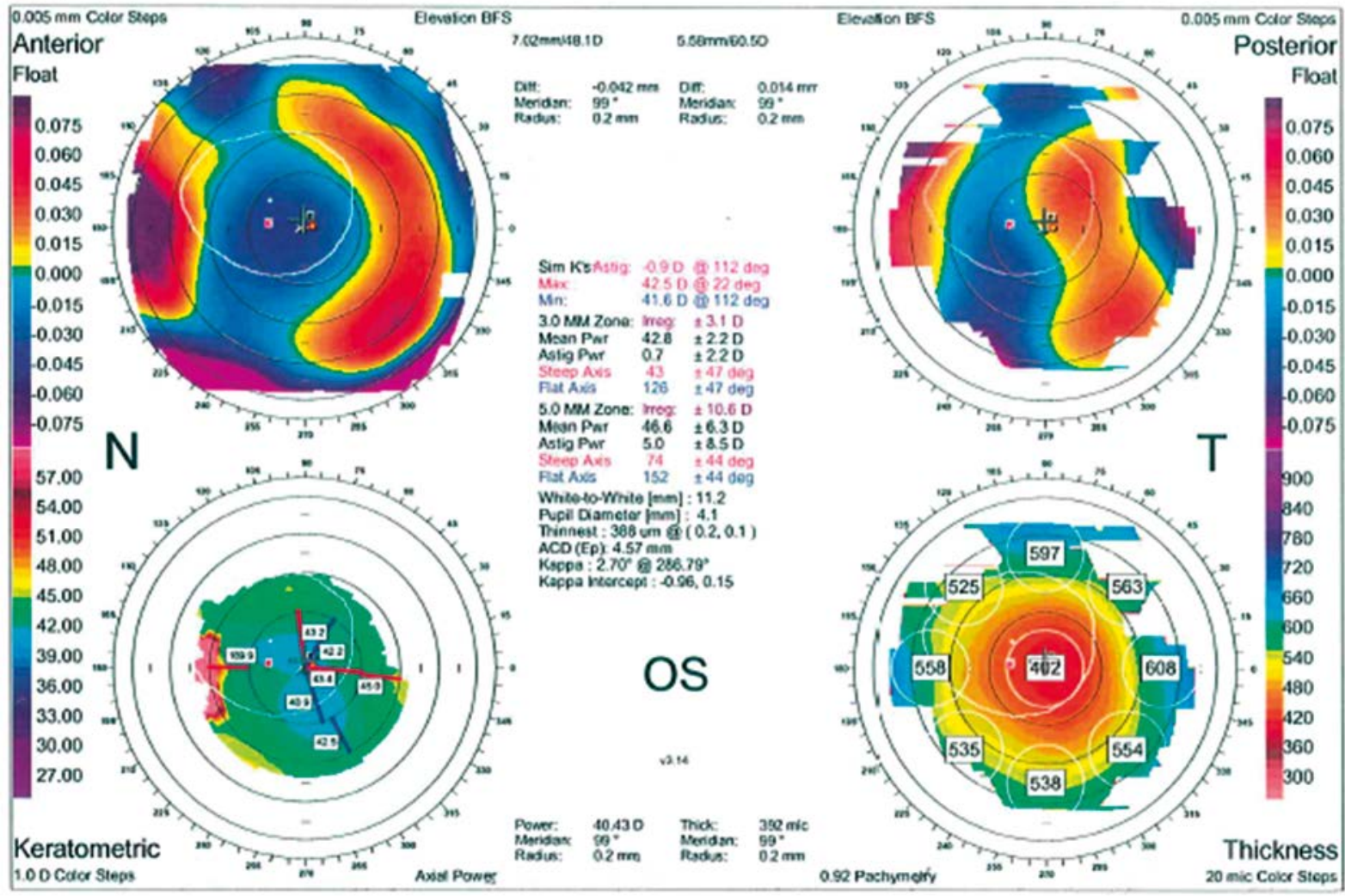

Photo 3. Slit-scanning corneal topography (Orbscan by Orbtek Bausch \& Lomb) showing corneal astigmatism 2 years and 5 months after laser refraction surgery - LASEK

likelihood. Retrospective appliance of CART to our case shows $3.1 \%$ probability of vision loss, i.e. $96.9 \%$ probability of vision survival. Both models were assessed in a prospective study of 100 open globe injuries at the Sunderland Eye Infirmary by Man et al. in 2010 [24]. The OTS and CART proved to have $97.4 \%$ and $93.5 \%$ sensitivity to predict visual survival and $100 \%$ and $73.9 \%$ specificity to predict no vision, respectively.

Over a span of 65 months the patient underwent multiple procedures including primary wound repair, penetrating keratoplasty combined with extracapsular cataract extraction, neodymium : YAG laser capsulotomy, and LASEK, and had a successfully treated episode of corneal graft rejection. This sequence of treatment substantially improved his left eye vision from hand movements at presentation to 0.9-0.5 $\times$ 90 maintained at the last follow-up nearly 10 years after the trauma.

In 2012 Andreoli et al. retrospectively analyzed 848 cases of open globe injuries treated at the Mas-

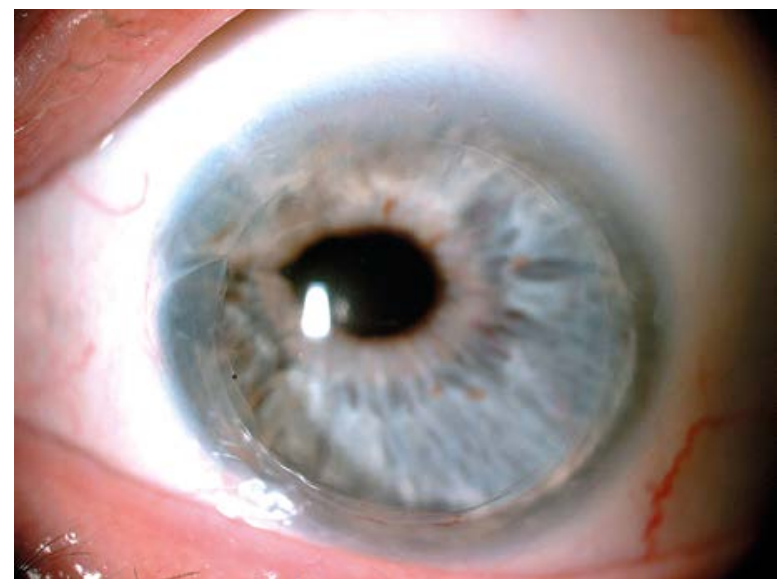

Photo 4. Slit-lamp photography showing the patient's left eye at the final visit following all surgical procedures. Note the clear corneal graft, nasal corneal scar and nasally drawn pupil

sachusetts Eye and Ear Infirmary [25]. They found that on average patients required 1.7 operations including open globe repair, whereas in our case there 
were 3 (one of which was combined). However, in their study the mean follow-up time was 19.7 months with the longest one of 73 months as compared to 119 months in our case. They also found that the following characteristics were correlated with higher number of operations: more severe ocular trauma score, worse initial visual acuity, retinal hemorrhage, anterior vitrectomy, pars plana vitrectomy, and lensectomy at primary repair, of which only low VA and anterior vitrectomy occurred in our case.

\section{Conclusions}

Proper initial surgical management of an open globe injury can create the possibility for a virtually complete restoration of vision. Awareness of what it means in your patient's eyes to be a professional ophthalmologist [26] as well as the art of incorporation of that knowledge into clinical practice may be the key to surgical success. This increases the chance of a long-term follow-up and enhances the patient's willingness to undergo multiple procedures which may lead to an excellent visual outcome (Photo 4). Moreover, it is worth highlighting that extended observation time of various eye conditions is a valuable source per se of clinical experience [27].

\section{References}

1. Tsuda Y, Wakiyama H, Amemiya T. Ocular injury caused by an air bag for a driver wearing eyeglasses. Jpn J Ophthalmol 1999; 43: 239-40.

2. Gault JA, Vichnin MC, Jaeger EA, Jeffers JB. Ocular injuries associated with eyeglass wear and airbag inflation. J Trauma 1995; 38: 494-7.

3. Piven I, Ben-Simon G. Foreign body from an eyeglass screw. Ophthalmology 2010; 117: 641.

4. Pieramici DJ, Sternberg P Jr, Aaberg TM Sr, et al. A system for classifying mechanical injuries of the eye (globe). The Ocular Trauma Classification Group. Am J Ophthalmol 1997; 123: 820-31.

5. Kuhn F, Morris R, Witherspoon CD. Birmingham Eye Trauma Terminology (BETT): terminology and classification of mechanical eye injuries. Ophthalmol Clin North Am 2002; 15: 139-43.

6. Rahman I, Maino A, Devadason D, Leatherbarrow B. Open globe injuries: factors predictive of poor outcome. Eye 2006; 20: 1336-41.

7. Gilbert CM, Soong HK, Hirst LW. A two-year prospective study of penetrating ocular trauma at the Wilmer Ophthalmological Institute. Ann Ophthalmol 1987; 19: 104-6.

8. Martin DF, Meredith TA, Topping TM, et al. Perforating (throughand-through) injuries of the globe. Surgical results with vitrectomy. Arch Ophthalmol 1991; 109: 951-6.
9. Brinton GS, Aaberg TM, Reeser FH, et al. Surgical results in ocular trauma involving the posterior segment. Am J Ophthalmol 1982; 93: 271-8.

10. Sternberg P Jr, de Juan E Jr, Michels RG, Auer C. Multivariate analysis of prognostic factors in penetrating ocular injuries. Am J Ophthalmol 1984; 98: 467-72.

11. Rao LG, Ninan A, Rao KA. Descriptive study on ocular survival, visual outcome and prognostic factors in open globe injuries. Indian J Ophthalmol 2010; 58: 321-3.

12. Entezari M, Rabei HM, Badalabadi MM, Mohebbi M. Visual outcome and ocular survival in open-globe injuries. Injury 2006; 37: 633-7.

13. Han SB, Yu HG. Visual outcome after open globe injury and its predictive factors in Korea. J Trauma 2010; 69: E66-72.

14. Barr CC. Prognostic factors in corneoscleral lacerations. Arch Ophthalmol 1983; 101: 919-24.

15. Rofail M, Lee GA, O'Rourke P. Prognostic indicators for open globe injury. Clin Experiment Ophthalmol 2006; 34: 783-6.

16. Pieramici DJ, Au Eong KG, Sternberg P Jr, Marsh MJ. The prognostic significance of a system for classifying mechanical injuries of the eye (globe) in open-globe injuries. I Trauma 2003; 54: 750-4.

17. Hatton MP, Thakker MM, Ray S. Orbital and adnexal trauma associated with open-globe injuries. Ophthal Plast Reconstr Surg 2002; 18: 458-61.

18. Cruvinel Isaac DL, Ghanem VC, Nascimento MA, et al. Prognostic factors in open globe injuries. Ophthalmologica 2003; 217: 431-5.

19. Wang YN, Shen LJ, Wang CG, et al. Prognosis of traumatic eyes with no light perception undergone vitrectomy and analysis of risk factors. Zhonghua Yan Ke Za Zhi 2007; 43: 340-5.

20. Andreoli MT, Andreoli CM. Geriatric traumatic open globe injuries. Ophthalmology 2011; 118: 156-9.

21. Mansouri M, Faghihi H, Hajizadeh F, et al. Epidemiology of openglobe injuries in Iran: analysis of 2,340 cases in 5 years (report no. 1). Retina 2009; 29: 1141-9.

22. Kuhn F, Maisiak R, Mann L, et al. The Ocular Trauma Score (OTS). Ophthalmol Clin North Am 2002; 15: 163-5.

23. Schmidt GW, Broman AT, Hindman HB, Grant MP. Vision survival after open globe injury predicted by classification and regression tree analysis. Ophthalmology 2008; 115: 202-9.

24. Man CY, Steel D. Visual outcome after open globe injury: a comparison of two prognostic models: the Ocular Trauma Score and the Classification and Regression Tree. Eye 2010; 24: 84-9.

25. Andreoli MT, Andreoli CM. Surgical rehabilitation of the open globe injury patient. Am J Ophthalmol 2012; 153: 856-60.

26. Davis RL, Wiggins MN, Mercado CC, O'Sullivan PS. Defining the core competency of professionalism based on the patient's perception. Clin Experiment Ophthalmol 2007; 35: 51-4.

27. Puchalska-Niedbat L, Modrzejewska M, Kulik U. Rapid onset anterior segment complication following diode laser photocoagulation for retinopathy of prematurity: a case report. Videosurgery Miniinv 2013; 8: 90-3.

Received: 5.05.2013, accepted: 15.06.2013. 